Supplement of Hydrol. Earth Syst. Sci., 25, 5473-5491, 2021

https://doi.org/10.5194/hess-25-5473-2021-supplement

(c) Author(s) 2021. CC BY 4.0 License.

(c) (i)

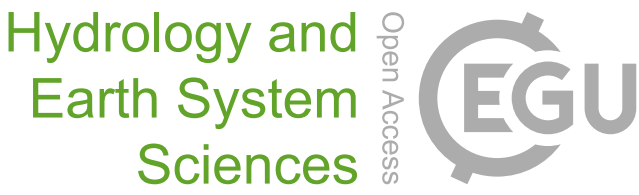

Supplement of

\title{
Unshielded precipitation gauge collection efficiency with wind speed and hydrometeor fall velocity
}

Jeffery Hoover et al.

Correspondence to: Jeffery Hoover (jeffery.hoover@canada.ca)

The copyright of individual parts of the supplement might differ from the article licence. 
The supplement includes additional details of the computational fluid dynamics (CFD) model including the method (Sect. S1), results (Sect. S2), and discussion of model results and comparison with previous studies (Sect. S3).

\section{S1 Modelling method}

\section{S1.1 Computational fluid dynamics model}

5 A high-resolution 3-dimensional computer aided design model of the Geonor T-200B3 $600 \mathrm{~mm}$ capacity gauge (hereafter Geonor gauge) with $2 \mathrm{~m}$ gauge orifice height was developed for the analysis using SolidWorks engineering software (Fig. S1). The Geonor gauge was modelled with a $200 \mathrm{~cm}^{2}$ orifice, $3.15 \mathrm{~mm}$ orifice thickness, and full $360 \mathrm{~mm}$ length inlet extending down into the gauge housing. SolidWorks Flow Simulation software (SolidWorks, 2019) was used to simulate the timeaveraged 3-dimensional flow around the unshielded precipitation gauge. Favre-averaged Navier-Stokes equations were used

10 to relate the fluid density, velocity components, viscous shear stress, Reynolds (turbulence) stress tensor, and mass distributed external force per unit mass, with contributions from porous media resistance, gravitational acceleration, and the coordinate systems rotation. The fluid was modelled as isothermal and incompressible. Bulk turbulence through the fluid was captured using the $k-\varepsilon$ turbulence model with $5 \%$ turbulence intensity at the inlet (Kato and Launder, 1993). A modified wall functions approach using Van Driest's profile was used to characterize the flow in the near-wall region (SolidWorks, 2013, 2019).

15 The domain width was $7 \mathrm{~m}$ and height was $8 \mathrm{~m}$ to achieve undisturbed flow at the edges of the domain and ensure uniform flow near the modeled gauge. The length of the domain was $18 \mathrm{~m}$ to allow hydrometeors to be released from a horizontal plane in the free-stream airflow ahead of the gauge (Fig. S1, Table S1). The ground was modelled as an adiabatic frictionless wall, with horizontal wind speeds $\left(U_{\mathrm{w}}\right)$ applied in $1 \mathrm{~m} \mathrm{~s}^{-1}$ increments from 0 to $10 \mathrm{~m} \mathrm{~s}^{-1}$. A finite-volume approach with rectangular parallelepipeds for fluid cells and polyhedrons at fluid solid interfaces was used for mesh generation. A clustered mesh with

20 first- order refinement around the gauge $(8 \mathrm{~mm}$ cells) and secondary refinement of $2 \mathrm{~mm}$ cells around the mounting post, gauge, and orifice ( 8.3 million cells in total) was used to resolve the nonlinear updraft velocity profile around the leading edge of the gauge rim and fluid dynamics in the area of the orifice. Simulations for each of the wind speeds were run to convergence for mass, energy, and momentum with model details summarized in Table S1.

25 Table S1. Computational fluid dynamics and Lagrangian hydrometeor tracking model

\begin{tabular}{ll}
\hline Component & Description \\
\hline Model & $\begin{array}{l}\text { Favre-averaged Navier-Stokes, steady-state, } k-\varepsilon, \text { isothermal, incompressible, } \\
\text { gravitational acceleration } a_{\mathrm{z}}=-9.81 \mathrm{~m} \mathrm{~s}^{-2}\end{array}$ \\
& Air (gas): molecular mass $0.02896 \mathrm{~kg} \mathrm{~mol}^{-1}$ \\
Fluid & Ground: ideal wall (adiabatic, frictionless) \\
Boundary conditions & $P=101325 \mathrm{~Pa}, T=293.2 \mathrm{~K}$, \\
Initial and ambient conditions & $U_{\mathrm{w}}=0,1,2, \ldots, 10 \mathrm{~m} \mathrm{~s}^{-1}$ (free-stream wind speed along $x$ )
\end{tabular}


Domain

Mesh

Hydrometeor injection

Hydrometeor tracking
Length $\mathrm{x}=18 \mathrm{~m}$, width $\mathrm{y}=7 \mathrm{~m}$, height $\mathrm{z}=8 \mathrm{~m}$

8.3 million cells, $y_{\text {mean }}^{+}=2.5 y_{\max }^{+}=15.1\left(U_{\mathrm{w}}=1 \mathrm{~m} \mathrm{~s}^{-1}\right)$,

$$
y_{\text {mean }}^{+}=17.2 y_{\text {max }}^{+}=90.8\left(U_{\mathrm{w}}=10 \mathrm{~m} \mathrm{~s}^{-1}\right)
$$

Horizontal injection rectangle:

length $\mathrm{x}=5.5 \mathrm{~m}$, width $\mathrm{y}=0.4 \mathrm{~m}$, height $\mathrm{z}=2$ to $8 \mathrm{~m}$

100000 hydrometeors/rectangle ( 4.5 hydrometeors $/ \mathrm{cm}^{2}$ )

Lagrangian, uncoupled, spherical hydrometeors, elastic wall reflection inside gauge orifice

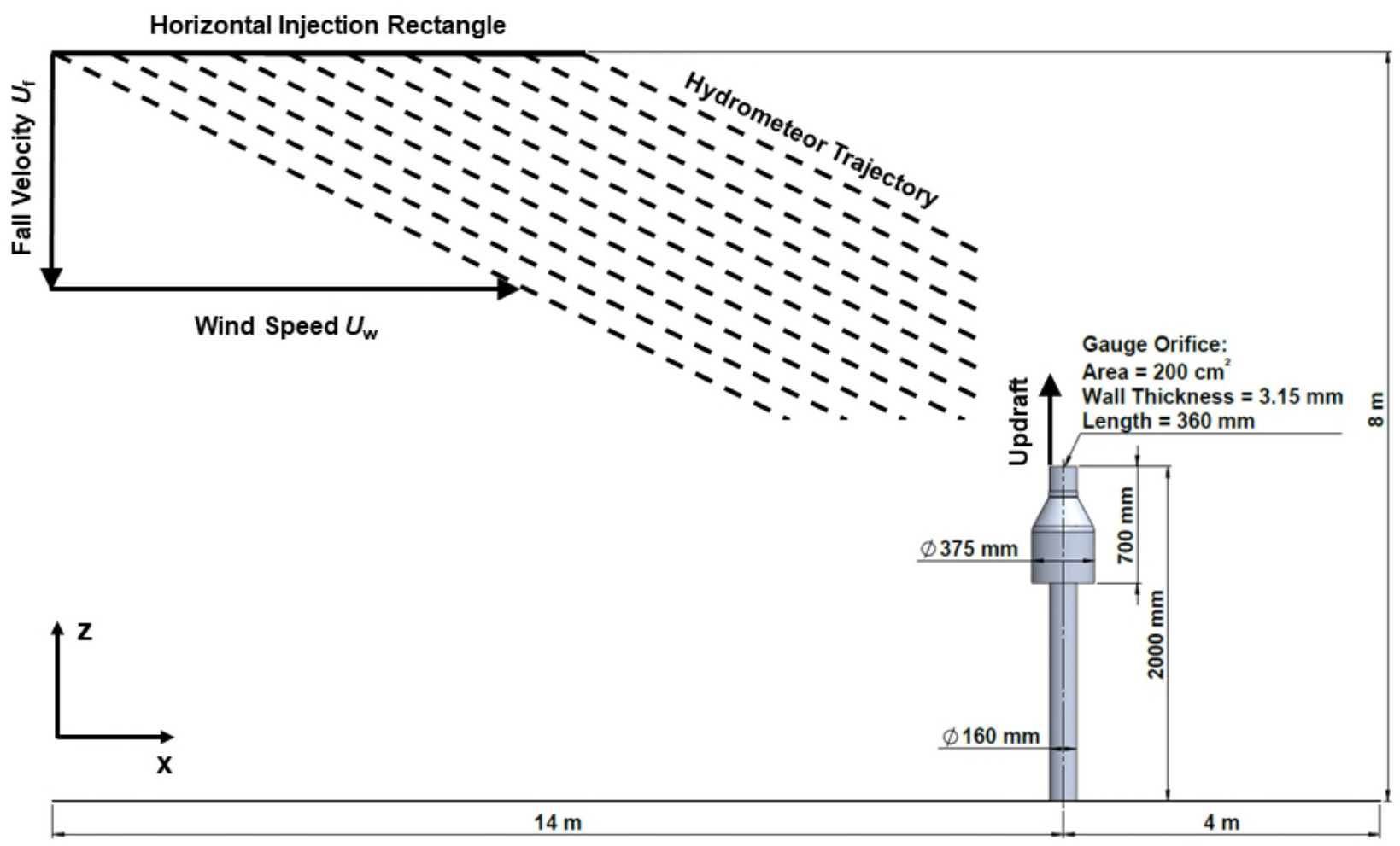

Figure S1. Unshielded Geonor T-200B3 600mm capacity gauge and model geometry, including computational domain with ground, 30 horizontal hydrometeor injection rectangle, free-stream hydrometeor trajectories based on wind speed and hydrometeor fall velocity and local updraft around leading edge of gauge orifice.

\section{S1.2 Collection efficiency based on hydrometeor fall velocity and wind speed}

For each wind speed, monodispersed hydrometeors were injected from a horizontal plane upstream and above the gauge orifice

35 (Fig. S1). Hydrometeor types were characterized by their fall velocity, diameter, density, and mass (Table S2). For dry snow and wet snow, the hydrometeor sizes are related to the fall velocity by a general power law (Rasmussen et al., 1999). The fall 
velocity for dry snow $\left(U_{\mathrm{dry}}\right)$ in $\mathrm{cm} \mathrm{s}^{-1}$ is a function of the size $\left(D_{\mathrm{dry}}\right)$ in $\mathrm{cm}$, with a similar relationship for wet snow (Eqs. S1a and $b$ ).

$U_{\text {dry }}=107 D_{\text {dry }}^{0.2}$,

$40 U_{\text {wet }}=214 D_{\text {wet }}{ }^{0.2}$,

For dry snow and wet snow, the hydrometeor density was chosen such that the size and fall velocity followed the power law relationship of Rasmussen et al. (1999), with the drag coefficient for spherical hydrometeors given by Henderson (1976) based on the relative hydrometeor to air velocity. This drag formulation closely matches that of Haider and Levenspiel (1989), and has been used in previous studies (Baghapour and Sullivan, 2017).

45

Table S2. Characteristics for rain, dry snowflake, wet snowflake, and ice pellet hydrometeors.

\begin{tabular}{lcccc}
\hline Description & $\begin{array}{c}\text { Diameter } \\
(\mathrm{m})\end{array}$ & $\begin{array}{c}\text { Density } \\
(\mathrm{kg} \mathrm{m}-3)\end{array}$ & $\begin{array}{c}\text { Mass } \\
(\mathrm{kg})\end{array}$ & $\begin{array}{c}\text { Fall Velocity } \\
\left(\mathrm{m} \mathrm{s}^{-1}\right)\end{array}$ \\
\hline Rain & $9.989 \mathrm{E}-05$ & $9.982 \mathrm{E}+02$ & $5.209 \mathrm{E}-10$ & 0.25 \\
Rain & $1.571 \mathrm{E}-04$ & $9.982 \mathrm{E}+02$ & $2.028 \mathrm{E}-09$ & 0.50 \\
Rain & $2.121 \mathrm{E}-04$ & $9.982 \mathrm{E}+02$ & $4.986 \mathrm{E}-09$ & 0.75 \\
Rain & $2.671 \mathrm{E}-04$ & $9.982 \mathrm{E}+02$ & $9.956 \mathrm{E}-09$ & 1.00 \\
Rain & $3.227 \mathrm{E}-04$ & $9.982 \mathrm{E}+02$ & $1.756 \mathrm{E}-08$ & 1.25 \\
Rain & $3.793 \mathrm{E}-04$ & $9.982 \mathrm{E}+02$ & $2.851 \mathrm{E}-08$ & 1.50 \\
Rain & $4.370 \mathrm{E}-04$ & $9.982 \mathrm{E}+02$ & $4.363 \mathrm{E}-08$ & 1.75 \\
Rain & $4.962 \mathrm{E}-04$ & $9.982 \mathrm{E}+02$ & $6.385 \mathrm{E}-08$ & 2.00 \\
Rain & $5.569 \mathrm{E}-04$ & $9.982 \mathrm{E}+02$ & $9.029 \mathrm{E}-08$ & 2.25 \\
Rain & $6.195 \mathrm{E}-04$ & $9.982 \mathrm{E}+02$ & $1.242 \mathrm{E}-07$ & 2.50 \\
Rain & $1.378 \mathrm{E}-03$ & $9.982 \mathrm{E}+02$ & $1.369 \mathrm{E}-06$ & 5.00 \\
Rain & $3.956 \mathrm{E}-03$ & $9.982 \mathrm{E}+02$ & $3.236 \mathrm{E}-05$ & 10.00 \\
Dry snow & $2.228 \mathrm{E}-04$ & $5.439 \mathrm{E}+02$ & $3.150 \mathrm{E}-09$ & 0.50 \\
Dry snow & $1.692 \mathrm{E}-03$ & $3.745 \mathrm{E}+01$ & $9.498 \mathrm{E}-08$ & 0.75 \\
Dry snow & $7.130 \mathrm{E}-03$ & $8.837 \mathrm{E}+00$ & $1.677 \mathrm{E}-06$ & 1.00 \\
Wet snow & $2.228 \mathrm{E}-04$ & $1.345 \mathrm{E}+03$ & $7.790 \mathrm{E}-09$ & 1.00 \\
Wet snow & $6.800 \mathrm{E}-04$ & $3.099 \mathrm{E}+02$ & $5.101 \mathrm{E}-08$ & 1.25 \\
Wet snow & $1.692 \mathrm{E}-03$ & $1.062 \mathrm{E}+02$ & $2.693 \mathrm{E}-07$ & 1.50 \\
Wet snow & $3.657 \mathrm{E}-03$ & $4.728 \mathrm{E}+01$ & $1.211 \mathrm{E}-06$ & 1.75 \\
Wet snow & $7.130 \mathrm{E}-03$ & $2.695 \mathrm{E}+01$ & $5.114 \mathrm{E}-06$ & 2.00 \\
Wet snow & $1.285 \mathrm{E}-02$ & $1.731 \mathrm{E}+01$ & $1.922 \mathrm{E}-05$ & 2.25 \\
Wet snow & $2.176 \mathrm{E}-02$ & $1.221 \mathrm{E}+01$ & $6.586 \mathrm{E}-05$ & 2.50 \\
Ice pellet & $1.472 \mathrm{E}-03$ & $9.167 \mathrm{E}+02$ & $1.532 \mathrm{E}-06$ & 5.00 \\
Ice pellet & $4.276 \mathrm{E}-03$ & $9.167 \mathrm{E}+02$ & $3.752 \mathrm{E}-05$ & 10.00 \\
\hline
\end{tabular}

For dry snow, hydrometeor fall velocities between $0.5 \mathrm{~m} \mathrm{~s}^{-1}$ to $1.0 \mathrm{~m} \mathrm{~s}^{-1}$ were included, representing sizes up to $7 \mathrm{~mm}$ and densities below that of ice (Table S2). Fall velocities for wet snow were selected between $1.0 \mathrm{~m} \mathrm{~s}^{-1}$ to $2.5 \mathrm{~m} \mathrm{~s}^{-1}$ for sizes

50 between 0.2 to $21.8 \mathrm{~mm}$. Spherical ice pellets with a density of $916.7 \mathrm{~kg} / \mathrm{m}^{3}$ were also included in the analysis for fall velocities of $5.0 \mathrm{~m} \mathrm{~s}^{-1}$ and $10.0 \mathrm{~m} \mathrm{~s}^{-1}$. Spherical hydrometeors with a density of $998.2 \mathrm{~kg} / \mathrm{m}^{3}$, representing rain, were included for fall velocities from $0.25 \mathrm{~m} \mathrm{~s}^{-1}$ to $10 \mathrm{~m} \mathrm{~s}^{-1}$ for comparison. 
The hydrometeor trajectory was derived from the drag force, gravitational force, and buoyancy forces acting on the hydrometeor as it moves through the flow using Lagrangian analysis. A dilute two-phase flow was assumed, where the

55 influence of the hydrometeors on the fluid flow was negligible and hydrometeor interactions including potential hydrometeor coalescence were ignored. Combining these forces gave the net hydrometeor acceleration $\left(\boldsymbol{a}_{\mathrm{p}}\right)$ as a function of the drag coefficient $\left(C_{\mathrm{D}}\right)$, hydrometeor cross sectional area $\left(A_{\mathrm{p}}\right)$, density of air $\left(\rho_{\mathrm{a}}\right)$, relative hydrometeor to air velocity $\left(\boldsymbol{u}_{\mathrm{p}}-\boldsymbol{u}_{\mathrm{a}}\right)$, hydrometeor density $\left(\rho_{\mathrm{p}}\right)$, hydrometeor volume $\left(V_{\mathrm{p}}\right)$, and acceleration due to gravity $(g)$ acting in the negative $\hat{\mathbf{z}}$ direction as shown in Eq. (S2).

$60 \boldsymbol{a}_{\mathrm{p}}=\frac{\mathrm{d} \boldsymbol{u}_{\mathrm{p}}}{\mathrm{dt}}=-\frac{C_{\mathrm{D}} \rho_{\mathrm{a}} A_{\mathrm{p}}\left|\boldsymbol{u}_{\mathrm{p}}-\boldsymbol{u}_{\mathrm{a}}\right|\left(\boldsymbol{u}_{\mathrm{p}}-\boldsymbol{u}_{\mathrm{a}}\right)}{2 \rho_{\mathrm{p}} V_{\mathrm{p}}}+\frac{\left(\rho_{\mathrm{a}}-\rho_{\mathrm{p}}\right) g}{\rho_{\mathrm{p}}} \hat{\mathbf{z}}$,

The hydrometeors were injected into the flow uniformly at equilibrium with an initial velocity $\left(\boldsymbol{u}_{\mathrm{p} 1}\right)$ equal to the free-stream wind speed $\left(U_{\mathrm{w}}\right)$ along the $\hat{\mathbf{x}}$ direction and hydrometeor fall velocity $\left(U_{\mathrm{f}}\right)$ in the negative $\hat{\mathbf{z}}$ direction (down).

$\boldsymbol{u}_{\mathrm{p} 1}=U_{\mathrm{w}} \hat{\mathbf{x}}-U_{\mathrm{f}} \hat{\mathbf{z}}$,

In the free-stream region under steady-state conditions, the hydrometeor fall velocity and terminal velocity will be equivalent.

65 Hydrometeor interactions with the inside of the gauge orifice were assumed to be ideal reflections.

The collection efficiency ( $\mathrm{CE}$ ) for a given free-stream wind speed $\left(U_{\mathrm{w}}\right)$ and hydrometeor fall velocity $\left(U_{\mathrm{f}}\right)$ corresponds to the ratio of the number of hydrometeors collected $\left(N_{\mathrm{C}}\right)$ over the horizontal gauge orifice area $\left(A_{\mathrm{C}}\right)$ to the number of hydrometeors injected from the horizontal injection plane above $\left(N_{\mathrm{I}}\right)$ over the horizontal injection plane area $\left(A_{\mathrm{I}}\right)$, as shown in Eq. (S4).

$70 \quad \mathrm{CE}\left(U_{\mathrm{w}}, U_{\mathrm{f}}\right)=\frac{\frac{N_{\mathrm{C}}}{A_{\mathrm{C}}}}{\frac{N_{\mathrm{I}}}{A_{\mathrm{I}}}}=\frac{N_{\mathrm{C}} A_{\mathrm{I}}}{N_{\mathrm{I}} A_{\mathrm{C}}}$,

\section{S1.3 Integral collection efficiency with wind speed}

The collection efficiency presented in Sect. S1.2 was for monodispersed hydrometeors with identical size, mass, density and fall velocity. In this section, we define the integral collection efficiency as that derived over the entire hydrometeor size distribution and associated characteristics (e.g. fall velocity, density and volume).

\section{S1.3.1 Rainfall}

The total precipitation intensity $\left(P_{\text {Total }}\right)$ is a function of the hydrometeor size distribution $\left(N_{R}\right)$, density $\left(\rho_{\mathrm{p}}\right)$, volume $\left(V_{\mathrm{p}}\right)$, fall velocity $\left(U_{\mathrm{f}}\right)$, and density of water $\left(\rho_{\mathrm{w}}\right)$. 
$P_{\text {Total }}=\frac{1}{\rho_{\mathrm{w}}} \int_{0}^{\infty} N_{R}(D) \rho_{\mathrm{p}}(D) V_{\mathrm{p}}(D) U_{\mathrm{f}}(D) \mathrm{d} D$,

The hydrometeor size distribution (number of hydrometeors per unit size per unit volume) for raindrops $\left(N_{\mathrm{R}}\right)$ can be expressed

80 as a gamma distribution defined by the $N_{0 R}\left(\mathrm{~m}^{-3} \mathrm{~cm}^{-1-\mu}\right)$ parameter, exponential factor $\left(\Lambda_{R}\right)$ in $\mathrm{cm}^{-1}$, unitless exponent $(\mu)$, and hydrometeor diameter $(D)$ in $\mathrm{cm}$ as given by Ulbrich (1983).

$$
N_{\mathrm{R}}=N_{0 R} D^{\mu} e^{-\Lambda_{R} D},
$$

Assuming the product of the exponential factor and the maximum hydrometeor diameter is large, the exponential factor can be expressed in terms of the exponent and median volume diameter $\left(D_{0 R}\right)$ in $\mathrm{cm}$.

$85 \Lambda_{R}=\frac{3.67+\mu}{D_{0 R}}$,

The median volume diameter is determined based on the rainfall intensity $(R) \mathrm{in} \mathrm{mm} / \mathrm{hr}$ and the empirical constants $\varepsilon$ and $\delta$ for the specific rain type.

$$
D_{0 R}=\varepsilon R^{\delta},
$$

The value of the exponent $(\mu)$ will be positive or negative depending on the rain type (orographic, thunderstorm, stratiform,

90 or showers), corresponding to a concave up or down distribution when plotted on a $\log \left(N_{R}\right)$ versus $D$ plot. Orographic rain with an exponent less than zero corresponds to a concave up distribution with small droplets and low fall speed (Ramana et al., 1959) (Table S3). Thunderstorm rain with a concave down distribution corresponds to large drops and high fall speed (Blanchard, 1953).

The hydrometeor fall velocity for rainfall is given by Beard (1976). At standard air temperature and pressure, the rainfall

95 hydrometeor fall velocity $\left(U_{\mathrm{f}}\right)$ in $\mathrm{m} \mathrm{s}^{-1}$ is a function of the equivalent hydrometeor diameter $(D)$, acceleration due to gravity $(\mathrm{g})$, raindrop hydrometeor density (density of water $\left.\rho_{\mathrm{w}}=998.2 \mathrm{~kg} / \mathrm{m}^{3}\right)$, density of air $\left(\rho_{\mathrm{a}}=1.23 \mathrm{~kg} / \mathrm{m}^{3}\right)$, dynamic viscosity of air $\left(\eta=1.79 E-5 N \cdot s / m^{2}\right)$, and surface tension of water $\left(\sigma_{\mathrm{w}}=0.07199 \mathrm{~N} / \mathrm{m}\right)$.

Table S3. Rainfall parameters for gamma drop size distribution summarized by Ulbrich (1983).

\begin{tabular}{lccccl}
\hline Description & $\mu$ & $N_{0}$ & $\varepsilon$ & $\delta$ & Source \\
\hline Orographic rain & -1.03 & $9.82 \times 10^{3}$ & 0.055 & 0.28 & Ramana et al. (1959) \\
Thunderstorm rain & 1.01 & $1.24 \times 10^{6}$ & 0.101 & 0.18 & Blanchard (1953) \\
\hline
\end{tabular}

100 The integral collection efficiency is the ratio of the precipitation intensity that is captured by the gauge to that which is falling in the free-stream airflow for a given hydrometeor size distribution, following the approach of Nešpor and Sevruk (1999). The collection efficiency is implicitly dependent on the equivalent hydrometeor diameter through the hydrometeor fall velocity. 
$\mathrm{CE}_{\mathrm{R}, \text { Integral }}=\frac{\int_{0}^{\infty} \mathrm{CE}\left(U_{\mathrm{w}}, U_{\mathrm{f}}\right) D^{3} N_{R}(D) U_{\mathrm{f}}(D) \mathrm{d} D}{\int_{0}^{\infty} D^{3} N_{R}(D) U_{\mathrm{f}}(D) \mathrm{d} D}$,

\section{S1.3.2 Snowfall}

105 The total precipitation intensity $\left(P_{\mathrm{S}, \text { Total }}\right)$ for snowfall is a function of the hydrometeor size distribution for snowfall $\left(N_{\mathrm{S}}\right)$, density $\left(\rho_{\mathrm{p}}\right)$, volume $\left(V_{\mathrm{p}}\right)$, fall velocity $\left(U_{\mathrm{f}}\right)$ and density of water $\left(\rho_{\mathrm{w}}\right)$, integrated over the range of equivalent diameters ( D).

$P_{\mathrm{S}, \text { Total }}=\frac{1}{\rho_{\mathrm{w}}} \int_{0}^{\infty} N_{\mathrm{S}}(D) \rho_{\mathrm{p}}(D) V_{\mathrm{p}}(D) U_{\mathrm{f}}(D) \mathrm{d} D$,

Taking the equivalent snowfall diameter as that for a spherical water droplet with the density of water gives the total

110 precipitation intensity integral as a function of the snowfall size distribution. Using this approach, both the size distribution and fall velocities of snowflakes are defined as a function of the equivalent spherical diameter of water droplets.

$$
P_{\mathrm{S}, \text { Total }}=\frac{\pi}{6} \int_{0}^{\infty} D^{3} N_{\mathrm{S}}(D) U_{\mathrm{f}}(D) \mathrm{d} D,
$$

The size distribution for snowflakes $\left(N_{\mathrm{S}}\right)$ can be expressed by the Gunn and Marshall size distribution (Gunn and Marshall, 1957) as a function of the size distribution parameter $\left(N_{0 S}\right)$ in $\mathrm{m}^{-1} \mathrm{~mm}^{-1}$, exponential factor $\left(\Lambda_{S}\right)$ in $\mathrm{cm}^{-1}$, and equivalent

115 spherical water drop diameters $(D)$ in $\mathrm{cm}$ above $0.1 \mathrm{~cm}$.

$N_{\mathrm{S}}=N_{0 \mathrm{~S}} e^{-\Lambda_{\mathrm{S}} D}$,

The size distribution parameter and exponential factor vary with the precipitation intensity $(R)$ in $\mathrm{mm} \mathrm{h}^{-1}$.

$N_{0 \mathrm{~S}}=3.8 \times 10^{3} R^{-0.87}$,

$\Lambda_{\mathrm{S}}=25.5 R^{-0.48}$,

120 The median volume diameter ( $\left.D_{0 \mathrm{~s}}\right)$ in $\mathrm{cm}$ varies with the exponential factor as shown by Atlas (1953).

$D_{0 \mathrm{~S}}=\frac{3.67}{\Lambda_{\mathrm{S}}}$,

The fall velocity $U_{\mathrm{f}}$ in $\mathrm{cm} \mathrm{s}^{-1}$ for various snowfall types, based on the equivalent spherical diameter of water droplets $(D)$ in $\mathrm{cm}$, is given by a general power law.

$U_{\mathrm{f}}=a D^{b}$,

125 The fall velocity power law coefficients for dendrites, rimed dendrites, and a mixture of dendrites and aggregates of plates is summarized in Table S4 based on the work of Langleben (1954). 
Table S4. Snowfall fall velocity parameters with power law formulation for equivalent water droplet diameter.

\begin{tabular}{lccl}
\hline Description & $a$ & $b$ & Source \\
\hline Dendrites & 178 & 0.372 & Langleben (1954) \\
Rimed dendrites & 210 & 0.283 & Langleben (1954) \\
Mixture of dendrites and aggregate of plates & 366 & 0.611 & Langleben (1954) \\
\hline
\end{tabular}

130 The integral collection efficiency at a given wind speed is the ratio of the precipitation intensity that is captured by the gauge to that which is falling in the free-stream airflow for a given crystal habit and size distribution. As with that for rainfall, the collection efficiency is implicitly dependent on the equivalent hydrometeor diameter through the hydrometeor fall velocity.

$\mathrm{CE}_{\mathrm{S}, \text { Integral }}=\frac{\int_{0}^{\infty} \mathrm{CE}\left(U_{\mathrm{w}}, U_{\mathrm{f}}\right) D^{3} N_{\mathrm{S}}(D) U_{\mathrm{f}}(D) \mathrm{d} D}{\int_{0}^{\infty} D^{3} N_{\mathrm{S}}(D) U_{\mathrm{f}}(D) \mathrm{d} D}$,

\section{S2 Modelling results}

\section{S2.1 Fall velocity impacts on collection efficiency}

Computational fluid dynamics simulations that included the time-averaged effects of flow turbulence were run for free-stream wind speeds between 0 and $10 \mathrm{~m} \mathrm{~s}^{-1}$ for the unshielded Geonor precipitation gauge. For visualization purposes, hydrometeor trajectories are illustrated for the $3 \mathrm{~m} \mathrm{~s}^{-1}$ wind speed case with fall velocities of $0.5 \mathrm{~m} \mathrm{~s}^{-1}, 1.0 \mathrm{~m} \mathrm{~s}^{-1}, 1.5 \mathrm{~m} \mathrm{~s}^{-1}$ and $2.0 \mathrm{~m} \mathrm{~s}^{-1}$ in Fig. S2. As the fall velocity increases, the hydrometeor approach angle from the horizontal increases, based on the relative

140 magnitudes of the wind speed and fall velocity. For the $2.0 \mathrm{~m} \mathrm{~s}^{-1}$ hydrometeor fall velocity, it is apparent that the hydrometeor trajectories experience little change due to the local airflow around the gauge (Fig. S2d). For lower fall velocities, the deflection due to the updraft around the leading edge of the gauge is more apparent, with the $0.5 \mathrm{~m} \mathrm{~s}^{-1}$ fall velocity hydrometeors closely coupled to the flow upward and over the gauge, with a few hydrometeors drawn in at the back side of the gauge orifice (Fig. S2a). For each of the hydrometeor injections, the same horizontal spacing of hydrometeors is present prior to encountering the

145 local airflow around the gauge. The number of hydrometeors captured is reduced for lower hydrometeor fall velocities at the same wind speed. At $3 \mathrm{~m} \mathrm{~s}^{-1}$ wind speed, rainfall hydrometeors with $0.25 \mathrm{~m} \mathrm{~s}^{-1}$ hydrometeor fall velocity are all carried over the gauge, corresponding to a collection efficiency of zero (not shown). 

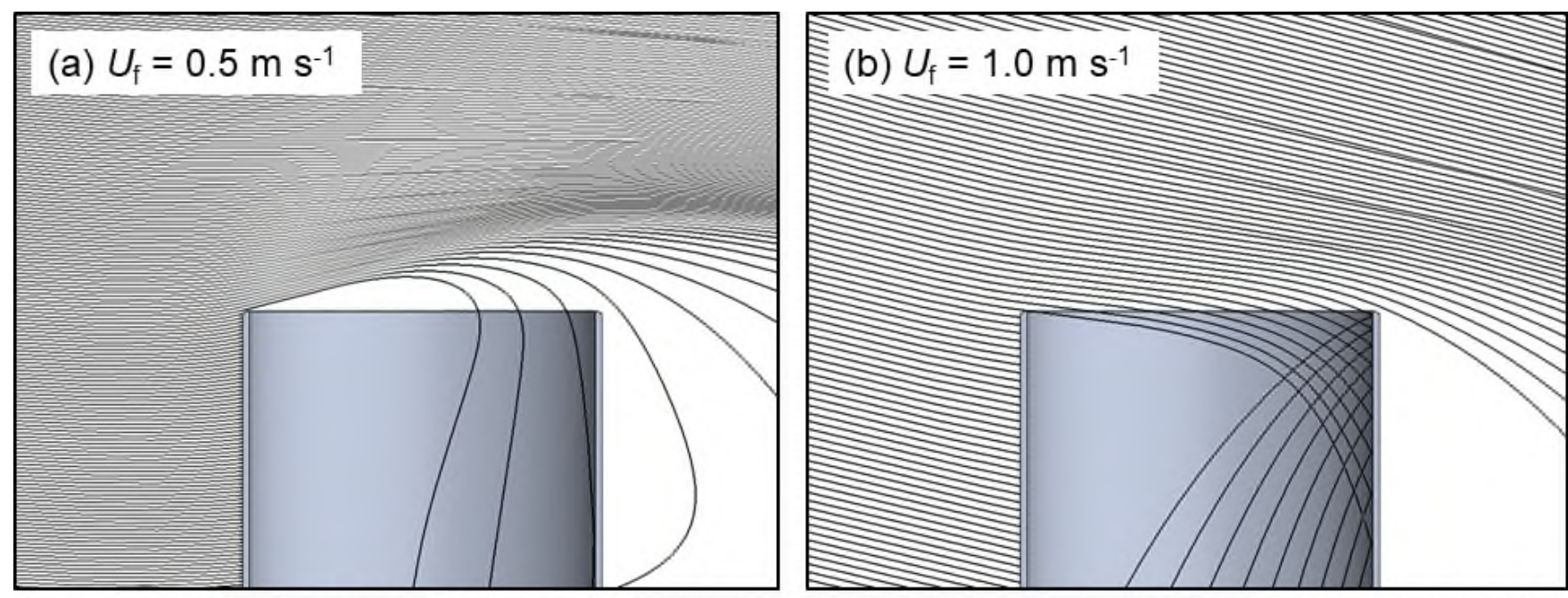

(c) $U_{\mathrm{f}}=1.5 \mathrm{~m} \mathrm{~s}^{-1}$

(d) $U_{\mathrm{f}}=2.0 \mathrm{~m} \mathrm{~s}^{-1}$
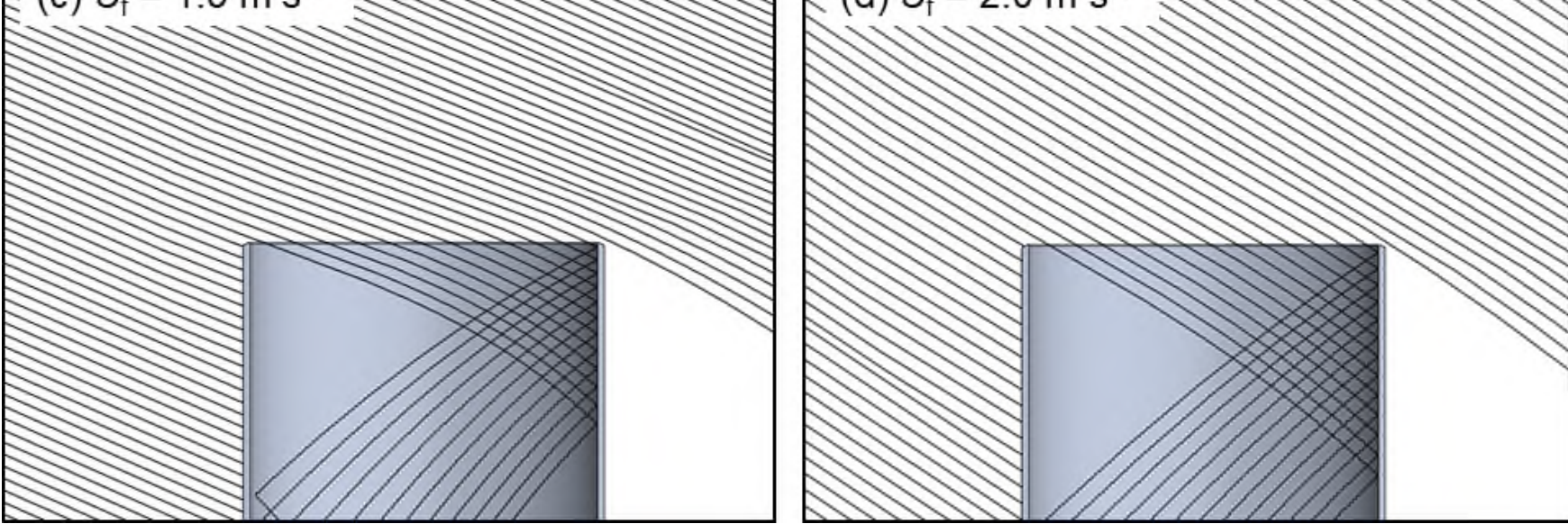

Figure S2. Flow simulation results showing hydrometeor trajectories for $3 \mathrm{~m} \mathrm{~s}^{-1}$ free-stream wind velocity with rain hydrometeor fall velocity of (a) $0.5 \mathrm{~m} \mathrm{~s}^{-1}$, (b) $1.0 \mathrm{~m} \mathrm{~s}^{-1}$, (c) $1.5 \mathrm{~m} \mathrm{~s}^{-1}$, and (d) $2.0 \mathrm{~m} \mathrm{~s}^{-1}$.

\section{S2.2 Application of CFD transfer function to hydrometeor size distributions}

\section{S2.2.1 Wind speed dependence of integral collection efficiency}

For specified hydrometeor types and precipitation intensities, the integral collection efficiency (Eqs. S9 and S17) was derived for wind speeds from 0 to $10 \mathrm{~m} \mathrm{~s}^{-1}$ using the CFD transfer function (Eq. 6) based solely on wind speed and hydrometeor fall velocity. The collection efficiency, derived using the CFD transfer function, decreases nonlinearly with wind speed, decreasing more rapidly at lower wind speeds and more gradually at higher wind speeds above approximately $5 \mathrm{~m} \mathrm{~s}^{-1}$ (Fig. S3). A wide 

intensity.

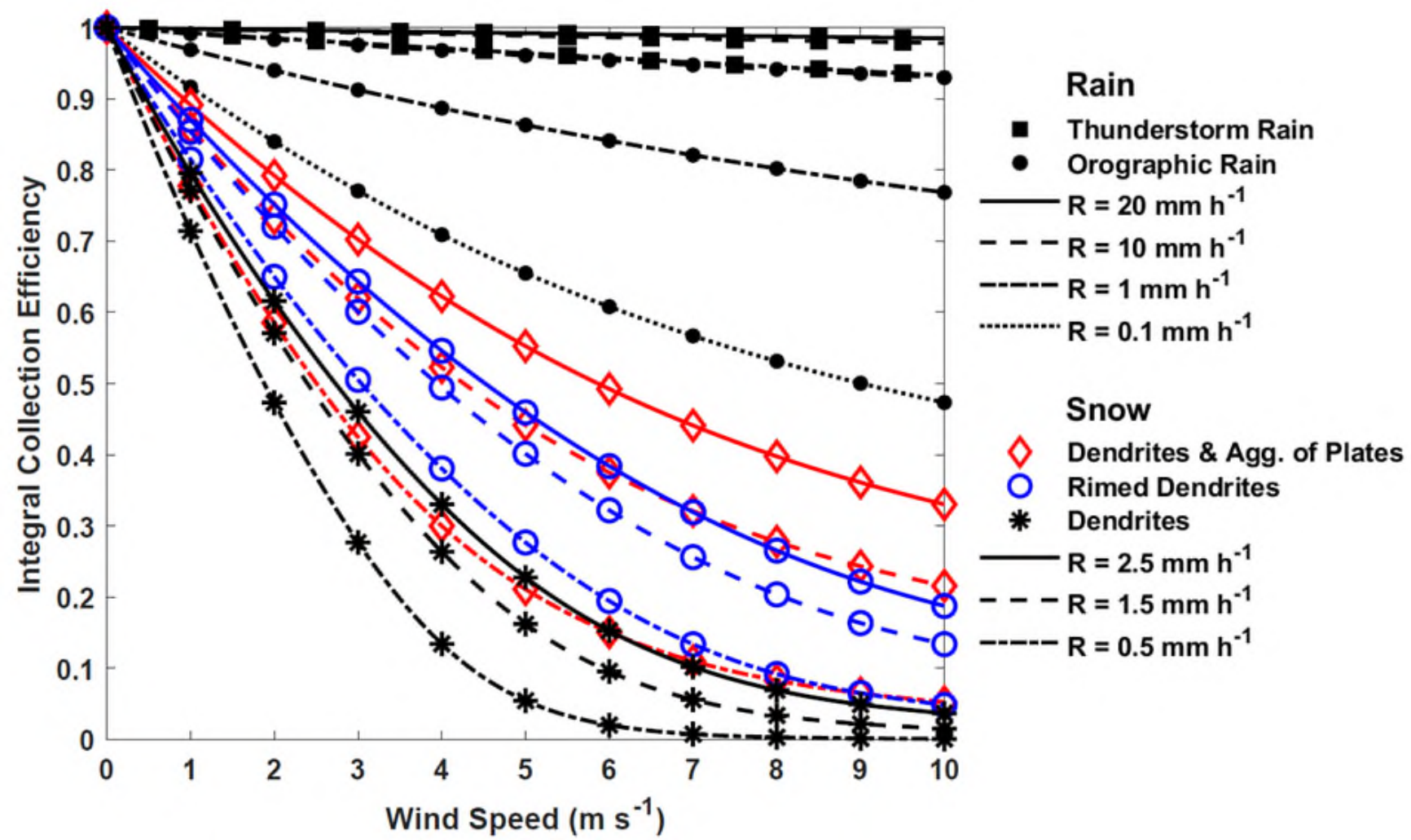

Figure S3. Integral Geonor unshielded gauge collection efficiency with wind speed for thunderstorm rain at $20 \mathrm{~mm} \mathrm{~h}^{-1}, 10 \mathrm{~mm} \mathrm{~h}^{-1}$, and 1 $\mathrm{mm} \mathrm{h}^{-1}$ precipitation intensities (R); orographic rain at $10 \mathrm{~mm} \mathrm{~h}^{-1}, 1 \mathrm{~mm} \mathrm{~h}^{-1}$, and $0.1 \mathrm{~mm} \mathrm{~h}^{-1}$ precipitation intensities (R); and aggregates of plates, rimed dendrites, and dendrites at $2.5 \mathrm{~mm} \mathrm{~h}^{-1}, 1.5 \mathrm{~mm} \mathrm{~h}^{-1}$, and $0.5 \mathrm{~mm} \mathrm{~h}^{-1}$ precipitation intensities (R).

Lower integral collection efficiencies are observed for snowfall relative to orographic and thunderstorm rain. Across snowfall types, a wide range of integral collection efficiency values are apparent. Dendrites show the greatest nonlinearity with wind speed and the lowest integral collection efficiency, with the latter decreasing to 0.01 at $6.7 \mathrm{~m} \mathrm{~s}^{-1}$ wind speed and $0.5 \mathrm{~mm} \mathrm{~h}^{-1}$ precipitation intensity. The integral collection efficiency continues to decrease with increasing wind speed, remaining small, but non-zero, up to $10 \mathrm{~m} \mathrm{~s}^{-1}$ wind speed. For $1.5 \mathrm{~mm} \mathrm{~h}^{-1}$ and $2.5 \mathrm{~mm} \mathrm{~h}^{-1}$ intensities, integral collection efficiencies are higher, with the magnitude of the increase varying with the wind speed. It is important to note the more gradual decrease in integral collection efficiency for wind speeds above $\sim 6 \mathrm{~m} \mathrm{~s}^{-1}$ compared with the results in Fig. 2 for a given hydrometeor fall velocity.

175 The integral collection efficiency includes the contribution from a range of hydrometeor sizes, including larger hydrometeors with higher fall velocities that are still able to be captured by the gauge, providing small but non-zero integral collection efficiencies. 
For comparison, integral collection efficiency results were computed for dry snow and wet snow using the same hydrometeor size distribution parameters as Colli et al. (2016b) for sizes between $0.25 \mathrm{~mm}$ to $20 \mathrm{~mm}$. The results from the different models show good agreement (Fig. S4). For dry snow, the integral collection efficiency decreases more gradually with wind speed in the present study than the Colli et al. (2016a) results, with collection efficiency values up to 0.18 higher at $3 \mathrm{~m} \mathrm{~s}^{-1}$ wind speed using the present model. For wet snow, the results of Colli et al. (2016a) show a nonlinear decrease in collection efficiency above $5 \mathrm{~m} \mathrm{~s}^{-1}$ wind speed that is not apparent in the results from the present study. As a result, the present study predicts up to 0.16 higher collection efficiency at $8 \mathrm{~m} \mathrm{~s}^{-1}$ wind speed.

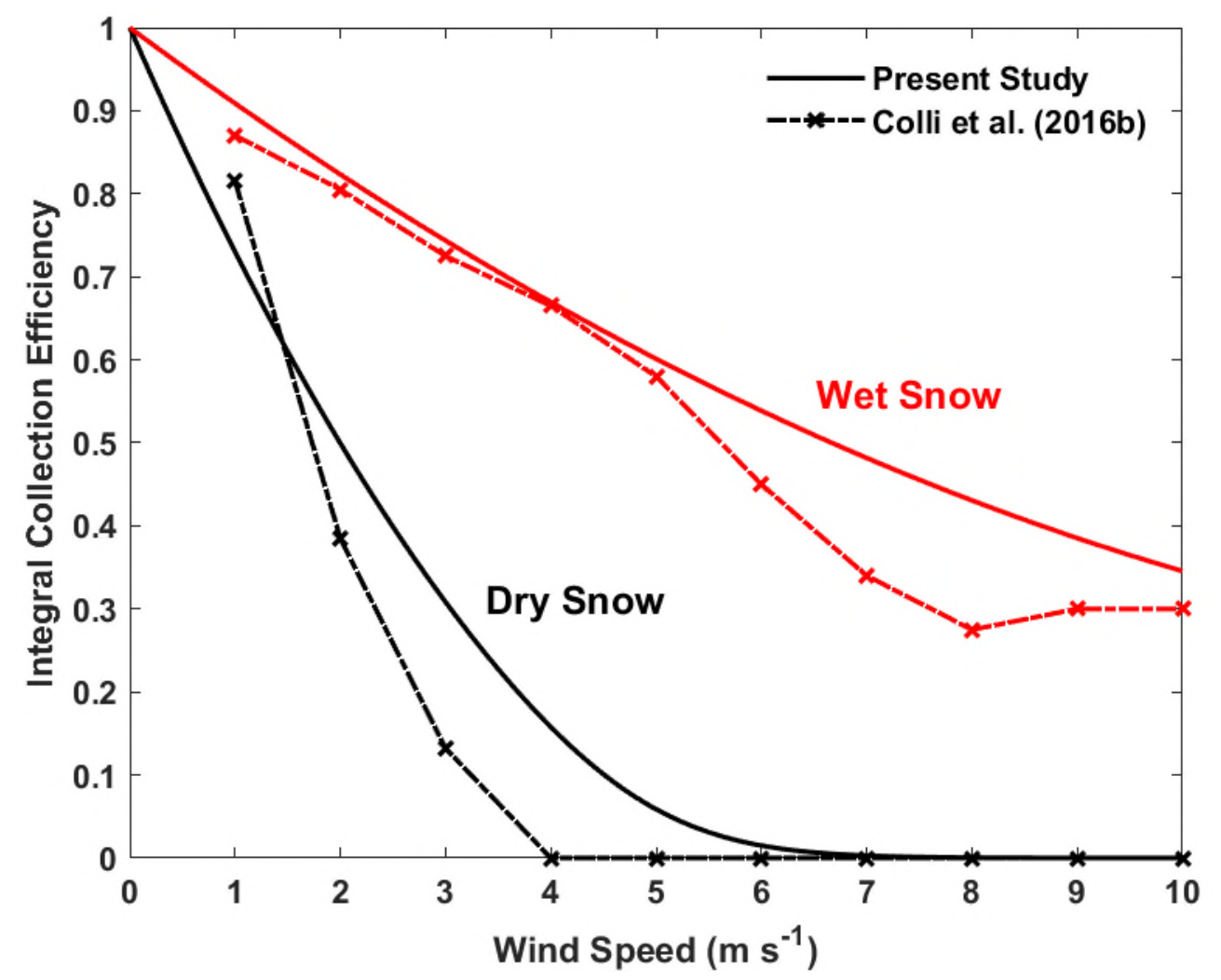

Figure S4. Integral Geonor unshielded gauge collection efficiency with wind speed for present study and Colli et al. (2016b) $k$ - $\omega$ SST model for dry snow and wet snow with Colli et al. (2016b) size distribution.

\section{S2.2.2 Precipitation intensity dependence of integral collection efficiency}

Using the CFD transfer function, integral collection efficiencies were derived for $0.5 \mathrm{~mm} \mathrm{~h}^{-1}, 1.5 \mathrm{~mm} \mathrm{~h}^{-1}$, and $2.5 \mathrm{~mm} \mathrm{~h}^{-1}$ precipitation intensities for three different snowfall types, between $0.1 \mathrm{~mm} \mathrm{~h}^{-1}$ and $10 \mathrm{~mm} \mathrm{~h}^{-1}$ for orographic rain, and between 
$1 \mathrm{~mm} \mathrm{~h}^{-1}$ and $10 \mathrm{~mm} \mathrm{~h}^{-1}$ for thunderstorm rain. The results are shown in Fig. S5 for selected wind speeds $\left(1 \mathrm{~m} \mathrm{~s}^{-1}, 3 \mathrm{~m} \mathrm{~s}^{-1}\right.$, and $\left.1956 \mathrm{~m} \mathrm{~s}^{-1}\right)$.

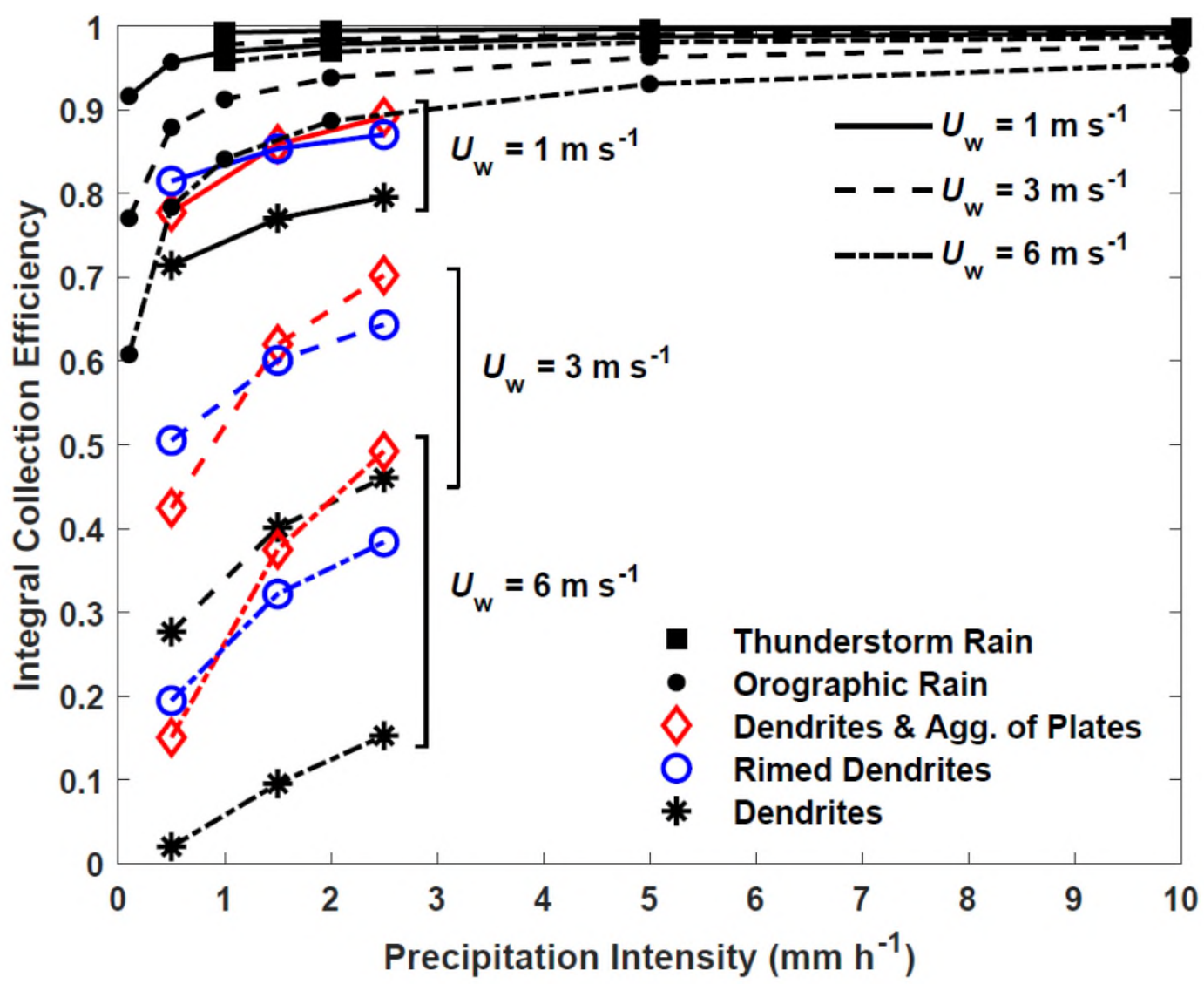

Figure S5. Integral Geonor unshielded gauge collection efficiency with precipitation intensity for rainfall and snowfall types at $1 \mathrm{~m} \mathrm{~s}^{-1}, 3 \mathrm{~m}$ $\mathrm{s}^{-1}$, and $6 \mathrm{~m} \mathrm{~s}^{-1}$ wind speeds.

Integral collection efficiencies increase with precipitation intensity and decrease with wind speed. For thunderstorm rain at 3 $\mathrm{m} \mathrm{s}^{-1}$ wind speed, the integral collection efficiency increases from 0.97 to 0.99 when the precipitation intensity increases from $1 \mathrm{~mm} \mathrm{~h}^{-1}$ to $10 \mathrm{~mm} \mathrm{~h}^{-1}$. For orographic rain, a sharp decrease in the integral collection efficiency is apparent with decreasing precipitation intensity below $1 \mathrm{~mm} \mathrm{~h}^{-1}$.

For all snowfall types, the integral collection efficiency is shifted to lower values relative to rain. The integral collection efficiency increases with precipitation intensity from 0.42 at $0.5 \mathrm{~mm} \mathrm{~h}^{-1}$ to 0.70 at $2.5 \mathrm{~mm} \mathrm{~h}^{-1}$ for dendrites and aggregates of plates at $3 \mathrm{~m} \mathrm{~s}^{-1}$ wind speed. Increasing the wind speed to $6 \mathrm{~m} \mathrm{~s}^{-1}$ further decreases the integral collection efficiency from 0.15 at $0.5 \mathrm{~mm} \mathrm{~h}^{-1}$ to 0.49 at $2.5 \mathrm{~mm} \mathrm{~h}^{-1}$. 
210 For dendrites and aggregates of plates, rimed dendrites, and dendrites, integral collection efficiencies are within 0.09 to 0.10 of one another for $0.5 \mathrm{~mm} \mathrm{~h}^{-1}$ precipitation intensities at $1 \mathrm{~m} \mathrm{~s}^{-1}$ wind speed. This range increases to 0.17 for $0.5 \mathrm{~mm} \mathrm{~h}^{-1}$ precipitation intensity and 0.34 for $2.5 \mathrm{~mm} \mathrm{~h}^{-1}$ precipitation intensity at $6 \mathrm{~m} \mathrm{~s}^{-1}$ wind speed. This provides an estimate of the overall variability in integral collection efficiency due to crystal habit if the precipitation intensity, wind speed, and the occurrence of snowfall are all known, but not the specific snowfall type. In cases where only the precipitation intensity and

215 wind speed is known, and the hydrometeor phase (rainfall or snowfall) and type is uncertain, the range of possible integral collection efficiencies grows dramatically. For example, at $6 \mathrm{~m} \mathrm{~s}^{-1}$ wind speed, the integral collection efficiencies for rain exceed 0.75 , while that for dendrites is below 0.16 ; hence, the catch efficiency in this case can vary by $\sim 0.74$ depending on the hydrometeor phase and type.

\section{S3 Modelling discussion}

\section{S3.1 Fall velocity impacts on collection efficiency}

The time-averaged numerical model describes the three-dimensional airflow around the unshielded Geonor gauge, including the updraft above the leading edge of the gauge orifice and downdraft at the back of the gauge orifice shown in previous studies (Thériault et al., 2012;Colli et al., 2016b;Baghapour et al., 2017). The updraft velocity increases sharply with height above the 225 leading edge of the gauge orifice, which appears to play an important role in the horizontal spreading and capture of hydrometeors, particularly for lower fall velocity hydrometeors (Fig. S2). These velocities scale with the wind speed, as shown previously by Colli et al. (2016b), and the relative magnitudes of the wind speed and hydrometeor fall velocity influence the collection efficiency. The hydrometeor fall velocity influences both the free-stream approach angle of hydrometeors before they encounter the local airflow around the gauge and the degree of coupling between the hydrometeor trajectories and the

230 local airflow. Hydrometeors with fall velocities above $2 \mathrm{~m} \mathrm{~s}^{-1}$ fall more vertically, and their paths show less deviation with the updraft and local airflow around the gauge orifice (Fig. S2). Hydrometeors with lower fall velocities have a smaller approach angle and are more closely coupled to the local airflow around the gauge orifice.

The numerical results for this study are based on a $5 \%$ inlet turbulence value that acts as a bulk turbulence in the atmosphere (Panofsky and Dutton, 1984) but may underestimate experimental results (Armitt and Counihan, 1968). A slip boundary 235 condition was modelled at the surface following the approach of previous studies (Baghapour and Sullivan, 2017;Baghapour et al., 2017). Further study with a no-slip wall condition under different turbulence conditions could lead to further insights into the influence of turbulence intensity on precipitation gauge collection efficiency. 


\section{S3.2 Application of CFD transfer function to hydrometeor size distributions}

240

\section{S3.2.1 Wind speed dependence of integral collection efficiency}

The integral collection efficiency decreases nonlinearly with wind speed depending on the hydrometeor type and fall velocity. Large differences in the integral collection efficiency dependence with wind speed are apparent across different hydrometeor types and intensities. Previous studies have shown similar differences across liquid (Nešpor and Sevruk, 1999;Jarraud, 2008) and solid hydrometeor types (Colli et al., 2016a;Colli et al., 2020;Thériault et al., 2012). The fall velocities of snowflakes are generally smaller than those of raindrops; accordingly, the collection efficiency for snowfall at a given wind speed is lower than that for rainfall (Fig. S3). Similarly, dendrites have lower fall velocities than rimed dendrites and columns and plates, and lower collection efficiency.

The integral collection efficiency results decrease continuously with increasing wind speed as the magnitude of the updraft at the leading edge of the gauge increases, free-stream hydrometeor trajectories decrease, and hydrometeors trajectories become more closely coupled with the local airflow around the gauge. For dendrites, the nonlinearity in the integral collection efficiency is more pronounced, as collection efficiencies decrease to small but finite values at higher wind speeds. This is due to the smaller number of hydrometeors with sufficient fall velocity to be captured by the gauge at higher wind speeds.

The differences in collection efficiency for different precipitation characteristics (type, habit, precipitation intensity) illustrate the large variability that can be expected when the characteristics or fall velocity are not considered. This variability presents

255 a particular challenge for mixed precipitation conditions, in which the precipitation type may not be well defined and can change rapidly over time. The proposed expression for the collection efficiency as a function of the wind speed and hydrometeor fall velocity (Eq. S18) provides a means of estimating the collection efficiency over different hydrometeor types and intensities, even if the precipitation type is not well defined.

The integral collection efficiency results using the CFD transfer function developed in the present study show good overall

260 agreement with the results of Colli et al. (2016a) for wet snow and dry snow, as shown in Fig. S4. Integral collection efficiency values in the present study are slightly higher than those of Colli et al. (2016a), attributed in part to the differences in the gauge geometry and hydrometeor drag model as discussed by Baghapour et al. (2017). The gauge geometry in the present study includes a refined orifice wall thickness and full-length orifice extending down into the gauge housing (Fig. S1). The peak velocities above the gauge in the present study are similar to those observed by Baghapour et al. (2017), who also used a refined orifice wall thickness and observed reduced peak velocities compared to the results of Colli et al. (2016a). Increases in the velocity magnitude over the gauge would be expected to decrease the collection efficiency in a manner similar to that for increased wind speed; hence, the higher peak velocities above the gauge in the results of Colli et al. (2016a) provide one explanation for the lower collection efficiency values observed.

The use of a continuous collection efficiency expression with wind speed and fall velocity dependence enables the derivation 270 of integral collection efficiencies over intermediate sizes and fall velocities in the hydrometeor size distribution. Collection efficiencies can be computed at intermediate wind speed values using this approach as well, providing the smooth integral 
collection efficiency curves shown in Fig. S4. Nešpor and Sevruk (1999) used a similar empirical approach for rain by developing an expression for the partial wind-induced error based on free-stream velocity and drop diameter applicable to Mk2, Hellman and ASTA gauges. The integral collection efficiency results of Colli et al. (2016b) were derived directly from numerical CE results for dry snow and wet snow at discrete sizes and wind speeds.

\section{S3.2.2 Precipitation intensity dependence of integral collection efficiency}

Knowledge of the precipitation type, intensity, and wind speed can provide a means for adjusting gauge catchment totals. For rainfall, the precipitation intensity has been shown to be an important parameter for the estimation of integral collection efficiency (Nešpor and Sevruk, 1999;Jarraud, 2008). A gradual increase in integral collection efficiency with precipitation intensity is observed for intensity values above $1 \mathrm{~mm} \mathrm{~h}^{-1}$ in Fig. S5. Below this intensity, the integral collection efficiency decreases more rapidly, with the rate of decrease depending on the rainfall type and wind speed. This is in general agreement with the results of Nešpor and Sevruk as presented in Jarraud (2008), who showed a sharper increase in the conversion factor (inverse of integral collection efficiency) below $1 \mathrm{~mm} \mathrm{~h}^{-1}$.

Integral collection efficiencies for snowfall also increase with precipitation intensity, as higher intensities correspond with larger numbers of hydrometeors with higher fall velocities and increased collection efficiencies, as shown by Colli et al. (2020). Integral collection efficiencies for snowfall can be much lower than for rain, depending on the wind speed. Differences are apparent across different snowfall crystal habits (e.g. dendrites vs. dendrites and aggregates of plates), with the magnitude of differences increasing with wind speed. This illustrates the difficulty of adjusting snowfall measurements if the crystal habit is not known. The range of possible integral collection efficiency values is even larger under conditions when solid, liquid,

290 and mixed precipitation can all be present. An additional challenge is presented by the measurement of low precipitation intensities for snowfall, where accumulations can be small relative to gauge uncertainties due to environmental factors (e.g. wind, temperature).

\section{S3.2.3 Hydrometeor fall velocity dependence of integral collection efficiency}

Integral collection efficiency differences across precipitation types are much smaller when stratified by wind speed and hydrometeor fall velocity (Fig. 5) than when stratified by wind speed and precipitation intensity (Fig. S5) or by wind speed alone (Fig. S3). This results from the ability of the hydrometeor fall velocity to capture differences in the integral collection efficiency across different hydrometeor types and precipitation intensities. The small differences in collection efficiency across different hydrometeor types with the same fall velocity are attributed to the varying contribution from higher fall velocity hydrometeors, with collection efficiencies approaching 1, in the mass-weighted distribution of hydrometeor fall velocities. 
Armitt, J., and Counihan, J.: The simulation of the atmospheric boundary layer in a wind tunnel, Atmospheric Environment, 2, 49-71, https://doi.org/10.1016/0004-6981(68)90019-x, 1968.

Atlas, D.: Optical extinction by rainfall, Journal of Meteorology, 10, 486-488, https://doi.org/10.1175/15200469(1953)010<0486:OEBR>2.0.CO;2, 1953.

305 Baghapour, B., and Sullivan, P. E.: A CFD study of the influence of turbulence on undercatch of precipitation gauges, Atmospheric Research, 197, 265-276, https://doi.org/10.1016/j.atmosres.2017.07.008, 2017.

Baghapour, B., Wei, C., and Sullivan, P. E.: Numerical simulation of wind-induced turbulence over precipitation gauges, Atmospheric Research, 189, 82-98, https://doi.org/10.1016/j.atmosres.2017.01.016, 2017.

Beard, K. V.: Terminal velocity and shape of cloud and precipitation drops aloft, J. Atmos. Sci., 33, 851-864, https://doi.org/10.1175/15200469(1976)033<0851:TVASOC>2.0.CO;2, 1976.

Blanchard, D. C.: Raindrop size distribution in Hawaiian rains, J. Meteor., 10, 457-473, https://doi.org/10.1175/15200469(1953)010<0457:RSDIHR>2.0.CO;2, 1953.

Colli, M., Lanza, L. G., Rasmussen, R., and Thériault, J. M.: The collection efficiency of shielded and unshielded precipitation gauges. Part II: Modeling particle trajectories., J. Hydromet., 17, 245-255, https://doi.org/10.1175/JHM-D-15-0011.1, 2016a.

315 Colli, M., Lanza, L. G., Rasmussen, R., and Thériault, J. M.: The collection efficiency of shielded and unshielded precipitation gauges. Part I: CFD airflow modeling, J. Hydromet., 17, 231-243, https://doi.org/10.1175/JHM-D-15-0010.1, $2016 \mathrm{~b}$.

Colli, M., Stagnaro, M., Lanza, L. G., Rasmussen, R., and Thériault, J. M.: Adjustments for Wind-Induced Undercatch in Snowfall Measurements Based on Precipitation Intensity, Journal of Hydrometeorology, 21, 1039-1050, https://doi.org/10.1175/JHM-D-19-0222.1, 2020.

320 Gunn, K. L. S., and Marshall, J. S.: The distribution with size of aggregate snowflakes, Journal of Meteorology, 15, 452-461, https://doi.org/10.1175/1520-0469(1958)015<0452:TDWSOA>2.0.CO;2, 1957.

Haider, A., and Levenspiel, O.: Drag coefficient and terminal velocity of spherical and nonsperical particles, Powder technology, 58, 63-70, https://doi.org/10.1016/0032-5910(89)80008-7, 1989.

Henderson, C. B.: Drag coefficients of spheres in continuum and rarefied flows, American Institute of Aeronautics \& Astronautics Journal, 14, 707-708, https://doi.org/10.2514/3.61409, 1976.

Jarraud, M.: Guide to meteorological instruments and methods of observation, World Meteorological Organization, Geneva, Switzerland, 2008.

Kato, M., and Launder, B.: The modelling of turbulent flow around stationary and vibrating square cylinders, Ninth Symposium of Turbulent Shear Flows, Kyoto, Japan, 1993.

330 Nešpor, V., and Sevruk, B.: Estimation of wind-induced error of rainfall gauge measurements using a numerical simulation, Journal of Atmospheric \& Oceanic Technology, 16, 450-464, https://doi.org/10.1175/1520-0426(1999)016<0450:EOWIEO>2.0.CO;2, 1999.

Panofsky, H. A., and Dutton, J. A.: Atmospheric turbulence: models and methods for engineering applications, Wiley-Interscience, 1984.

Ramana, M., Gupta, B. V., and Gupta, S. C.: Precipitation characteristics based on raindrop size measurements at Delhi and Khandala during southwest monsoon., J. Sci. Ind. Res., 18A, 352-371, 1959.

335 Rasmussen, R. M., Vivekanandan, J., Cole, J., Meyers, B., and Masters, C.: The estimation of snowfall rate using visibility, Journal of Applied Meteorology, 38, 1542-1563, https://doi.org/10.1175/1520-0450(1999)038<1542:TEOSRU>2.0.CO;2, 1999.

SolidWorks: Enhanced turbulence modeling in SolidWorks flow simulation, USAMKTURBMODWPENG0313, 2013.

SolidWorks: SolidWorks Flow Simulation Technical Reference, 2019.

Thériault, J. M., Rasmussen, R., Ikeda, K., and Landolt, S.: Dependence of Snow Gauge Collection Efficiency on Snowflake Characteristics, Journal of Applied Meteorology \& Climatology, 51, https://doi.org/10.1175/JAMC-D-11-0116.1, 2012.

Ulbrich, C. W.: Natural variations in the analytical form of the raindrop size distribution, Journal of Climate and Applied Meteorology, 22, 1764-1775, https://doi.org/10.1175/1520-0450(1983)022<1764:NVITAF>2.0.CO;2, 1983. 